\title{
Mechanisms of invasion resistance: competition among intertidal mussels promotes establishment of invasive species and displacement of native species
}

\author{
J. S. Shinen ${ }^{1, *}$, S. G. Morgan ${ }^{2}$ \\ ${ }^{1}$ Estación Costera de Investigaciones Marinas, Departamento de Ecología, Pontificia Universidad Católica de Chile, \\ Alameda 340, Santiago, Chile \\ ${ }^{2}$ Bodega Marine Laboratory, Department of Environmental Science and Policy, University of California Davis, PO Box 247, \\ Bodega Bay, California 94923, USA
}

\begin{abstract}
Understanding interactions between invasive species and recipient communities is essential to determining whether invasive species will become established and spread. In this study, we explored the role of competition and the specific mechanisms of interaction in limiting the spread of the Mediterranean bay mussel Mytilus galloprovincialis within a Pacific Northwest invasion front. We examined the role of direct (interference) and indirect (exploitation) mechanisms of competition among M. galloprovincialis and 2 native mussels (M. trossulus and M. californianus). As the fastestgrowing organisms are often competitively dominant in space-limited systems, such as rocky intertidal communities, we used changes in relative performance (growth and survival) in monocultures and polycultures to assess interactions among mussels. Performance of $M$. galloprovincialis was always greater than that of the 2 native species of mussels in both field and laboratory manipulations of species composition and density, indicating that interspecific competition did not strongly limit the growth or survival of the invader. Moreover, the presence of $M$. galloprovincialis consistently led to both reduced growth and survival of $M$. trossulus. Laboratory studies of mussel feeding and behavior revealed $M$. galloprovincialis to be a robust interference competitor. The invader restricted movement, smothered and interfered with filter feeding of the 2 native species of mussels. Rather than limiting invasion, interference competition gave $M$. galloprovincialis a competitive advantage over the native mussels. Our results suggest $M$. galloprovincialis may have contributed to the displacement of M. trossulus along much of its historic southern range.
\end{abstract}

KEY WORDS: Exploitation competition - Interference competition · Mytilus $\cdot$ Rocky intertidal communities

\section{INTRODUCTION}

A major ecological concern is the ability of communities to resist invasion by an exotic species. The classical hypothesis states that as species diversity increases, communities become increasingly saturated, leaving few available niches that can be colonized by invasive species (Elton 1958). Empirical studies have found both positive (Naeem et al. 2000, Stachowicz et al. 2002) and negative (Levine \& D'Antonio 1999, Stohlgren et al. 1999) relationships between diversity and invasibil- ity, yet these conclusions appear to depend heavily on the system, species, and scale being investigated (Fridley et al. 2007). Discrepancies may be attributed to a lack of understanding of the mechanisms that generate local patterns of community structure within invaded systems, such as interspecific competition, productivity, or environmental heterogeneity (Moore et al. 2001). However, predicting invasion resistance depends on understanding how mechanisms maintaining diversity suppress or facilitate an invader (Levine 2000). The ability of an exotic species to successfully 
invade a new community may depend on the strength and form of its competitive interactions with species in the recipient community (Morrison 2000, Brown et al. 2002). Although many studies of the interspecific competition between native and invasive species have demonstrated strong interspecific effects, comparatively few studies identify or directly examine the mechanisms of interaction (but see Callaway \& Aschehoug 2000, Duyck et al. 2006), and examples outside plant ecology are rare.

In marine systems, invasions of non-native species into resident communities are both contributions and threats to local biodiversity (Carlton 1996, Grosholz 2002), but competitive interactions between marine native and invasive species are poorly understood (but see Castilla et al. 2004). The Mediterranean bay mussel Mytilus galloprovincialis is a global invader with established populations in the Americas, Africa, Australasia, and Japan (McDonald et al. 1991, Sanjuan et al. 1997). The invasion of M. galloprovincialis has been particularly well documented in South Africa, where the non-native mussel has had wide-ranging effects on entire communities along exposed, wave-swept shores (reviewed by Branch \& Steffani 2004). Multi-trophic effects include competitive exclusion of native mussels (Van Erkom Schurink \& Griffiths 1990) and herbivorous limpets (Steffani \& Branch 2005), but the specific mechanisms of interaction between native mussels and M. galloprovincialis are not well understood.

Relatively little is known about the ecological influence of Mytilus galloprovincialis on native communities along the Pacific coast of North America. Since its introduction to San Diego harbor in the 1930s via shipping and aquaculture (Wonham 2004), M. galloprovincialis has spread and persisted throughout southern California (Geller 1999). A retrospective analysis of museum collections revealed that the invader may have displaced the native mussel, $M$. trossulus, throughout much of the southern portion of its range (Geller 1999). The invasion front is currently located along the California coast from north of Point Conception to south of Cape Mendocino. Within this region, M. galloprovincialis has become well established in protected bays and harbors but does not reach substantial numbers in open coast rocky intertidal communities (Geller 1999, Rawson et al. 1999). The exposed coasts of the region also receive sympatric recruitment of M. galloprovincialis, and 2 native mussels, M. trossulus and $M$. californianus (reviewed in Braby \& Somero 2006). M. californianus numerically dominates local rocky intertidal communities, and adult M. trossulus and M. galloprovincialis are rare and disproportionately scarce relative to the numbers of settlers.

The disjunction between the larval recruitment patterns and the adult mussel community structure within the Pacific Northwest invasion front indicates that post-settlement mortality partially constrains the ongoing invasion of Mytilus galloprovincialis north of Point Conception (Johnson \& Geller 2006). Predation, particularly by the whelk Nucella ostrina, restricts the distribution of both $M$. trossulus and M. galloprovincialis to some extent, but predation rates do not appear to be sufficient to limit invasion (Shinen et al. 2009). Moreover, a large settlement event of $M$. galloprovincialis could swamp the biotic resistance provided by predators (Hollebone \& Hay 2007).

Competition may also play an important role in the invasion of Mytilus galloprovincialis. In rocky intertidal communities, where available substrate for sessile organisms can be limiting, the fastest-growing species is often the competitive dominant. Early work by Harger (1968) conducted on a possible mixture of all 3 species of Mytilus suggests that competition may play an important role in mussel growth and mortality. Similarly in South Africa, the presence of M. galloprovincialis is frequently associated with a decline in the native mussel Perna perna (Bownes \& McQuaid 2006, Hanekom 2008). M. galloprovincialis, like other filter-feeding bivalve molluscs, may compete for resources (sestonic food or attachment substrate) directly by physical interference (crowding or pushing) or indirectly through exploitation (Frechette \& Despland 1999). Although primarily sessile, mussels do move using a modified muscular foot while releasing and attaching byssal threads and can engage in or disengage from competitive interactions. Movement and behavior can be extremely important in interference competition, where crowding and smothering can occur, as well as in exploitation competition, where individuals may move to better exploit resources. In this study, we examined competitive interactions among the 3 species of mussels to determine whether the 2 native mussels can resist further invasion by M. galloprovincialis. Specifically, we established the existence of a competitive hierarchy among these mussels, and identified and quantified the mechanisms of competitive interaction.

\section{MATERIALS AND METHODS}

General approach. All experiments were conducted at the Bodega Marine Laboratory (BML) or in the surrounding Bodega Marine Reserve (BMR) in northern California, USA. The region is characterized by mixed semidiurnal tides and strong oceanographic upwelling. All 3 species of mussels occur on exposed rocky shores of the BMR, although Mytilus californianus predominates.

In all experiments, changes in relative growth and survival rates among mussel monocultures and poly- 
cultures were used to estimate competitive ability (Connell 1983). Since small settlers of Mytilus trossulus and M. galloprovincialis can be difficult to differentiate morphologically (Martel et al. 2000), larger juvenile mussels that are readily distinguishable (length $26.8 \pm$ $3.8 \mathrm{~mm}$ ) were used in all experiments. Field studies of competitive interactions among more than 2 species are uncommon because they become unwieldy when all possible density controls for intraspecific competition are included. $M$. galloprovincialis and $M$. trossulus of appropriate size also were limiting, because thousands were needed for experiments. These constraints compelled us to combine a design that is ideal for distinguishing between interspecific and intraspecific competition with a replacement series design. Our substitutive design held total mussel density constant while species composition varied (Table 1,A). Treatments included 3 monocultures, 3 polycultures with 2 species (1:1), and 1 polyculture with 3 species (1:1:1). The substitutive use of 3 species among 2-species polycultures revealed species-specific effects between competitors while holding intraspecific effects constant. Our objective was to identify the possible existence of a competitive hierarchy among the 3 species rather than the absolute differences between interspecific and intraspecific effects, thereby reducing the need for intraspecific controls. However, 3 reduceddensity monocultures (40n) were included to estimate intraspecific effects in the field. Monoculture densities ideally would have been equal to the proportions within each of the polycultures (Underwood 1986), but mussels transplanted in low density at BMR often suffer high mortality making this intractable. Mussels are gregarious and need sufficient attachment matrix within mussel aggregations to prevent being swept from the substrate. The intraspecific monoculture density was selected to approximate the small mussel patches observed at BMR while ensuring transplant survival. Although the intraspecific control was not directly comparable to the polyculture treatments, precluding a determination of the absolute interaction strength, comparisons between high- and low-density monocultures revealed the approximate direction and magnitude of intraspecific effects.

To meet statistical assumptions, growth among species and within treatments was analyzed using the ANOVA of untransformed and rank-transformed data. Only probability values that were significant $(p<0.05)$ for both tests were accepted (Zar 1974). ANOVA was also performed on the arcsine square root of survivorship among species and within treatments. Post-hoc analyses were made with both Tukey's HSD multiple comparisons $(\alpha=0.05)$ (differences between all treatments) and Dunnett's tests $(\alpha=0.05)$ (using monoculture groups as controls).

Competitive hierarchy of native and invasive mussels in the field. The competitive hierarchy of the 3 species of mussels was determined in the field beginning in May 2004. Mussels were collected by hand from naturally occurring mid-intertidal mussel populations. Mytilus californianus were collected from BMR $\left(38^{\circ} 18^{\prime} 18^{\prime \prime} \mathrm{N}, 123^{\circ} 3^{\prime} 8^{\prime \prime} \mathrm{W}\right)$. M. trossulus were collected from Strawberry Hill, Oregon $\left(44^{\circ} 15^{\prime} 385^{\prime \prime} \mathrm{N}\right.$, $\left.124^{\circ} 07^{\prime} 594^{\prime \prime} \mathrm{W}\right)$, well north of the zone of sympatry of the 3 species of mussels. M. galloprovincialis were collected from Shell Beach in Tomales Bay, California $\left(38^{\circ} 06^{\prime} 59.75^{\prime \prime} \mathrm{N}, 122^{\circ} 52^{\prime} 23.93^{\prime \prime} \mathrm{W}\right)$, where the population is composed almost entirely of $M$. galloprovincialis

Table 1. Experimental design for monocultures and polycultures of Mytilus californianus (C), M. trossulus (T), and M. galloprovincialis $(\mathrm{G})$. Table shows numbers of mussels in each trial. Within each study, columns represent treatments, except for monoculture treatments, where each species was grown separately. Reduced-density monocultures were only included in the 2004 field study. The 2006 exploitation study included a control treatment where no mussels were present

\begin{tabular}{|c|c|c|c|c|c|c|c|}
\hline Experiment & Mussel sp. & $\begin{array}{c}\text { Reduced- } \\
\text { density } \\
\text { monoculture }\end{array}$ & $\begin{array}{c}\text { High- } \\
\text { density } \\
\text { monoculture }\end{array}$ & $\begin{array}{l}\text { 2-spp. } \\
\text { polyculture } \\
(\mathrm{C} \times \mathrm{T})\end{array}$ & $\begin{array}{l}\text { 2-spp. } \\
\text { polyculture } \\
(\mathrm{C} \times \mathrm{G})\end{array}$ & $\begin{array}{c}\text { 2-spp. } \\
\text { polyculture } \\
(\mathrm{G} \times \mathrm{T})\end{array}$ & $\begin{array}{l}\text { 3-spp. } \\
\text { polyculture } \\
(\mathrm{C} \times \mathrm{T} \times \mathrm{G})\end{array}$ \\
\hline (A) Field study (2004) & Total mussels & 40 & 60 & 60 & 60 & 60 & 60 \\
\hline $\mathrm{n}=6$ & M. californianus & 40 & 60 & 30 & 30 & - & 20 \\
\hline No. treatments $=10$ & M. trossulus & 40 & 60 & 30 & - & 30 & 20 \\
\hline$(20 \times 20 \times 10 \mathrm{~cm})$ & M. galloprovincialis & 40 & 60 & - & 30 & 30 & 20 \\
\hline (B) Interference study & \multicolumn{2}{|l|}{ Total mussels } & 12 & 12 & 12 & 12 & 12 \\
\hline$(2005) \mathrm{n}=5$ & M. californianus & (not done) & 12 & 6 & 6 & - & 4 \\
\hline No. treatments $=7$ & M. trossulus & (not done) & 12 & 6 & - & 6 & 4 \\
\hline$(42 \times 26 \times 17 \mathrm{~cm})$ & \multicolumn{2}{|c|}{ M. galloprovincialis (not done) } & 12 & - & 6 & 6 & 4 \\
\hline (C) Exploitation study & Total mussels & 0 (control) & 6 & 6 & 6 & 6 & 6 \\
\hline$(2006) n=6$ & M. californianus & - & 6 & 3 & 3 & - & 2 \\
\hline No. treatments $=8$ & M. trossulus & - & 6 & 3 & - & 3 & 2 \\
\hline$(42 \times 26 \times 17 \mathrm{~cm})$ & M. galloprovincialis & - & 6 & - & 3 & 3 & 2 \\
\hline
\end{tabular}


(Sarver \& Foltz 1993, Suchanek et al. 1997). To further reduce the inadvertent inclusion of non-target species or hybrids, each mussel was individually inspected for species-specific morphological features (McDonald et al. 1991). Mussels that did not resemble the target population were eliminated from the experiment. All mussels were transported to $\mathrm{BML}$, cleaned of any epibionts, and acclimated in species-specific, flowthrough seawater aquaria for $1 \mathrm{mo}$.

In June, the length, height, and width (mm) of mussels were recorded, and a small notch was made at the growing edge of each shell as a reference scar for new shell growth (Coe \& Fox 1942). Mussels were haphazardly assigned to experimental treatments, which were spatially randomized and outplanted to a previously cleared area of mussel bed in the middle intertidal mussel zone at the BMR. Stainless steel wire mesh $(7 \mathrm{~mm})$ enclosures $(20 \times 20 \times 10 \mathrm{~cm})$ were constructed around each of the experimental cultures and were bolted directly onto the rock. Mussels were held close to the rock surface for $2 \mathrm{wk}$ by flexible plastic mesh $(7 \mathrm{~mm})$ to facilitate reattachment to the substrate by byssal threads. In August, the enclosures were removed, and all of the mussels and mussel shells were transported back to the BML. Growth and survivorship of each species of mussel in each treatment were calculated. Cages were needed to eliminate emigration of mussels and exclude high densities of predatory whelks and seastars. The predator-exclusion cages were not completely invulnerable to small whelks, but shells that showed signs of predation (i.e. whelk drill holes) were minimal $(<5 \%)$, did not affect the relative densities of mussels, and were excluded from mortality estimates. Partialcage controls were not conducted, because full prevention of predation and emigration was essential and only relative changes in growth and survival in polyculture and monoculture were needed to interpret species interactions. Cages did not trap sediment or greatly restrict water flow on this highly energetic, wave-swept shore and had little effect on mussel performance. Indeed, growth and survival of mussels were generally consistent in field and in laboratory experiments indicating that competitive ability and species interactions were comparable in different flow regimes.

Interference competition in the laboratory. We also conducted an experiment in the laboratory to determine whether physical interference is an important mechanism of competition among the 3 species of mussels. Although laboratory conditions differ from those in the field, mussel behaviors during immersion are impossible to monitor in field conditions. In December 2004, mussels of each species were haphazardly assigned to monoculture and polyculture treatments (Table 1,B). The total number of mussels in each treatment was reduced to 12 to simplify the observation of mussel behaviors while maintaining the same relative proportions of species in the cultures that were used in the field. The reduced-density monoculture treatments were eliminated. Replacement series-type designs such as this can be valuable comparative tools (Cousens \& O'Neill 1993), where consistent patterns of mussel growth and survivorship between laboratory and field treatments may indicate conserved, densityindependent competitive interactions between species (Jolliffe 2000). Each mussel was notched, and length, height, and width were recorded before placing mussels into plastic containers $(42 \times 26 \times 17 \mathrm{~cm})$. Mussels in each container were arranged in a clump directly under a steady flow of sand-filtered seawater.

The experiment was terminated after 5 wk. Photographs were taken, and individual mussel position was noted in each of the monoculture and polyculture source containers. Mortality was recorded and growth increments above the filed notch were measured. The distance traveled by mussels from the original placement of clumped mussels was calculated with ImageJ software (Abramoff et al. 2004). Data were analyzed with ANOVA and post-hoc analyses were performed with both Tukey's HSD multiple comparisons $(\alpha=0.05)$ (differences between all treatments) and Dunnett's tests $(\alpha=0.05)$ (using monoculture groups as controls). Species-specific daily growth rates were also pooled over all treatments regressed against the total distance traveled $(\mathrm{cm})$ from the central mussel clump.

Exploitation competition in the laboratory. A series of feeding trials was conducted in the laboratory to determine whether the 3 species of mussels compete for food. As a proxy for filter-feeding ability, clearance rates of mussel cultures were assessed using 2 methods. First, we monitored the relative decline in concentration of in vivo chlorophyll a (chl a) over time. Work on related mussels has demonstrated that clearance rates are similar in both laboratory and in situ conditions (Velasco \& Navarro 2005). In April 2006, small mussels ( 2 to $4 \mathrm{~cm}$ length) of the 3 species of mussels were collected from the same collection sites over a single spring tide series and were transported to BMR. Mussels were acclimated in flow-through seawater for 1 mo before being assigned haphazardly to monoculture and polyculture treatments (Table 1,C). To limit movement, mussels were placed in small $(10 \mathrm{~cm}$ diameter) glass culture dishes, which were submerged in the center of larger plastic containers $(42 \times 26 \times 17 \mathrm{~cm})$ containing 11 liters of static, sand-filtered seawater. Each plastic container was supplied with a single weighted airline and air stone. Cultures were positioned in a randomized block design inside large tubs $(110 \times 110 \times 55 \mathrm{~cm})$. A $10 \mathrm{~cm}$ tall standpipe and running seawater in the large tubs kept the smaller plastic containers at ambient seawater temperature. 
Feeding trials lasted $6 \mathrm{~h}$, approximating the average immersion time for mussels in a semidiurnal tidal cycle. Concentrations of chl a were measured with a handheld fluorometer (Turner Designs Aquafluor). No-mussel controls were included in each replicate tub to monitor natural fluctuations in chl a during feeding trials. Initial water samples were taken before mussel cultures were added to containers and at 60 min intervals. Mean chl a concentrations per interval were quantified for each container by taking water samples $(1 \mathrm{ml})$ at 3 locations (top, middle, and bottom), at mid-depth in the aquaria. At the termination of the feeding trials, mussel tissue was dissected and dried at $60^{\circ} \mathrm{C}$ for a minimum of $24 \mathrm{~h}$ at the end of the experiment to determine the total dry mass of mussels in each culture.

Clearance rates of mussels in monocultures and polycultures were also assessed in terms of the total particulate matter (TPM) and the particulate organic matter (POM) removed over the course of the feeing trials. Changes in concentration of TPM and POM were estimated by taking 2 replicate water samples (1 l) before and after feeding trials. Samples were vacuum filtered onto pre-ashed, tared Whatman GF/C filters. TPM was determined after $24 \mathrm{~h}$ of drying at $60^{\circ} \mathrm{C}$. Total organic matter was calculated from the difference between the TPM and the filter weight after samples were ashed at $400^{\circ} \mathrm{C}$ for $4 \mathrm{~h}$.

Analyses were performed on the total percentage change in concentration of chl $a$, TPM, and POM at the end of each feeding trial. Values were standardized by the total dry tissue mass of mussels $(\mathrm{g})$ in each culture. No blocking effects were found; thus, differences in filter feeding between cultures were compared using ANOVA, and post-hoc analyses were performed with both Tukey's HSD multiple comparisons ( $\alpha=0.05$ ) (differences between all treatments) and Dunnett's tests ( $\alpha=0.05$ ) (using monoculture groups as controls).

\section{RESULTS}

\section{Competitive hierarchy of native and invasive mussels}

Growth and survival in field monocultures and polycultures suggest that Mytilus galloprovincialis is the dominant competitor in a space-limited competitive hierarchy (Fig. 1). The invader M. galloprovincialis grew 10 times faster than either of the 2 native species $\left(F_{2,2371}=688.34, \mathrm{p}<\right.$ 0.001). Additionally, the presence of $M$. gallo- provincialis in a 2-species polyculture with $M$. trossulus reduced growth and survival of $M$. trossulus, indicating that the invader can competitively displace this native species. M. californianus was weakly positively affected by interspecific interactions.

In addition to establishing the competitive robustness of Mytilus galloprovincialis, other interspecific and intraspecific effects were observed in cultures. However, these effects were secondary, since the strengths of these interactions were generally weak. $M$. californianus grew most slowly and seemed least affected by experimental conditions and treatments. However, this species tended to benefit from decreasing density of conspecifics in the field. $M$. trossulus was influenced by competition between conspecifics and the native competitor, $M$. californianus. The invader, M. galloprovincialis, was influ-
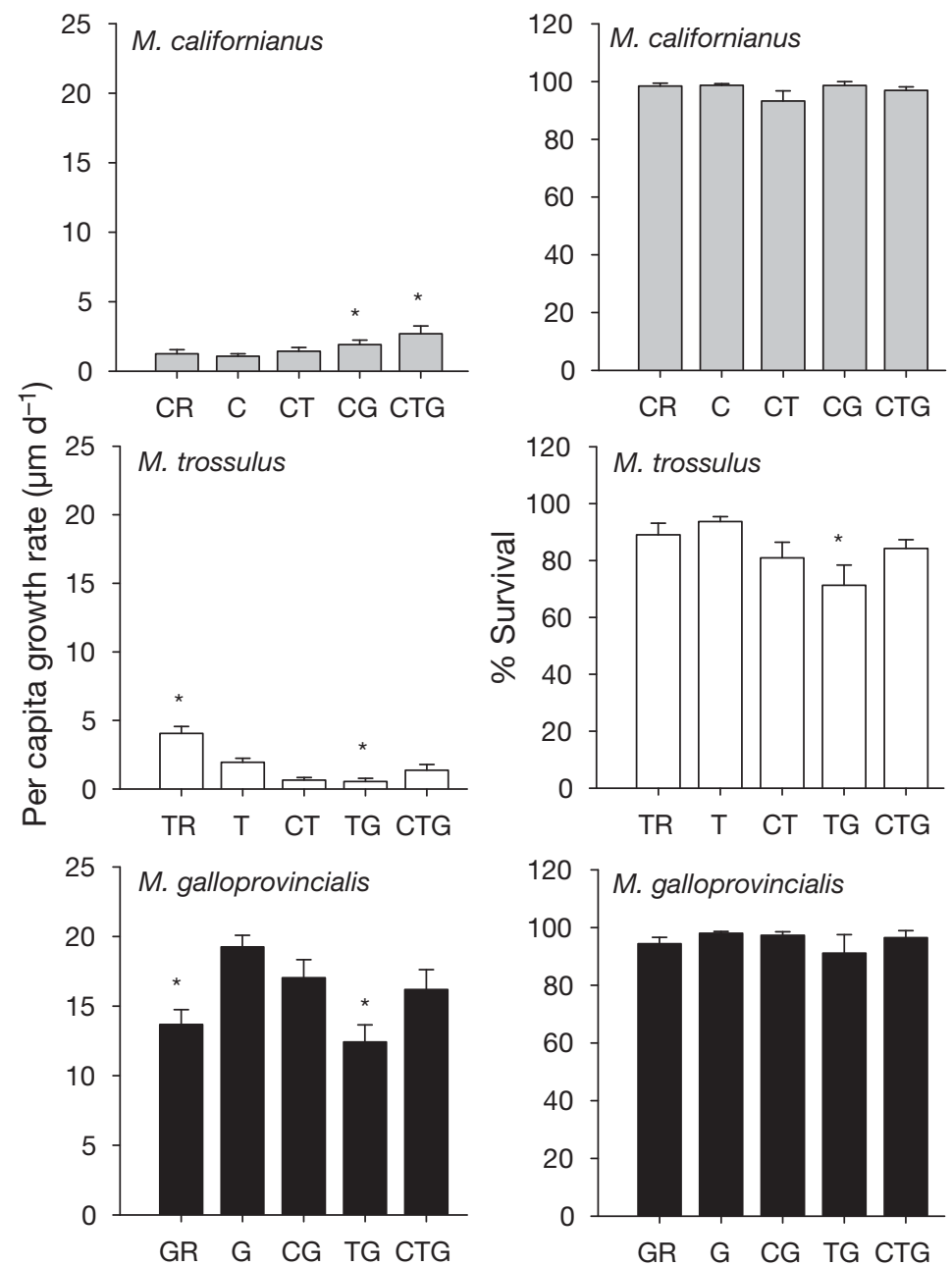

Fig. 1. Competitive hierarchy experiment. Mean per capita growth rates and percentage survival of 3 species of mussels within monocultures and polycultures: $\mathrm{C}=$ Mytilus californianus, $\mathrm{T}=M$. trossulus, $\mathrm{G}=$. galloprovincialis. $\mathrm{R}=$ reduced density. Bars indicate $+1 \mathrm{SE}$. ${ }^{*}$ Groups that differed significantly $(\mathrm{p}<0.05)$ from the high-density monoculture controls based on Dunnett's post-hoc analyses of both the untransformed and rank-transformed data 
enced by changes in total mussel density rather than competition between hetero- or conspecifics. The growth rate of the invader decreased only where total mussel density was reduced: in reduced-density monoculture and in field polyculture with $M$. trossulus, where $M$. trossulus experienced high mortality. Lastly, all 3 species experienced moderately higher performance in the 3-species polyculture than in 2-species polycultures, suggesting the mussels may benefit weakly from an indirect facilitation, particularly diffuse competition. Several of these tendencies were non-significant $(p>0.05)$, and none alter our main finding that the invader is a strong interference competitor.

\section{Interference competition}

Relative growth rates of the different mussels in the laboratory were consistent with those observed in the field (Fig. 2). Invasive Mytilus galloprovincialis grew the most, followed by $M$. trossulus and then $M$. californianus $\left(F_{2,408}=\right.$ 138.78, p < 0.001). The growth rate of native M. trossulus decreased in polyculture with invasive $M$. galloprovincialis, as it did in the field. Survival was generally high across all species and treatments (Fig. 2); however, all of the observed mortality occurred within mussel clumps where individuals appeared to be smothered by other mussels that had climbed atop the mussel clump. Mortality of native M. californianus was greatest overall $(\sim 15 \%$ total, $F_{2,57}=5.70, \mathrm{p}=0.006$ ).

All 3 species of mussels moved inside the plastic aquaria, and dispersal frequency and distance in the treatments varied by species and treatment (Fig. 3). Overall, Mytilus trossulus emigrated from mussel clumps more frequently $\left(F_{2,57}=5.79, \mathrm{p}=0.005\right)$ and farther $\left(F_{2,408}=10.44\right.$, $\mathrm{p}<0.001)$ than the other 2 species. The growth rate of $M$. trossulus had a moderately positive relationship to the distance traveled from the mussel clump $\left(R^{2}=0.24, p<\right.$ 0.001). However, only weakly positive relationships were observed between growth rate and distance traveled by native $M$. californianus $\left(\mathrm{R}^{2}=0.12, \mathrm{p}<0.001\right)$ and invasive $M$. galloprovincialis $\left(\mathrm{R}^{2}=0.02, \mathrm{p}<0.001\right)$.

\section{Exploitation competition}

Differences in clearance rate were observed among species and treatments in feeding trials (Fig. 4). Surprisingly, the mussel with the greatest growth rate, Mytilus
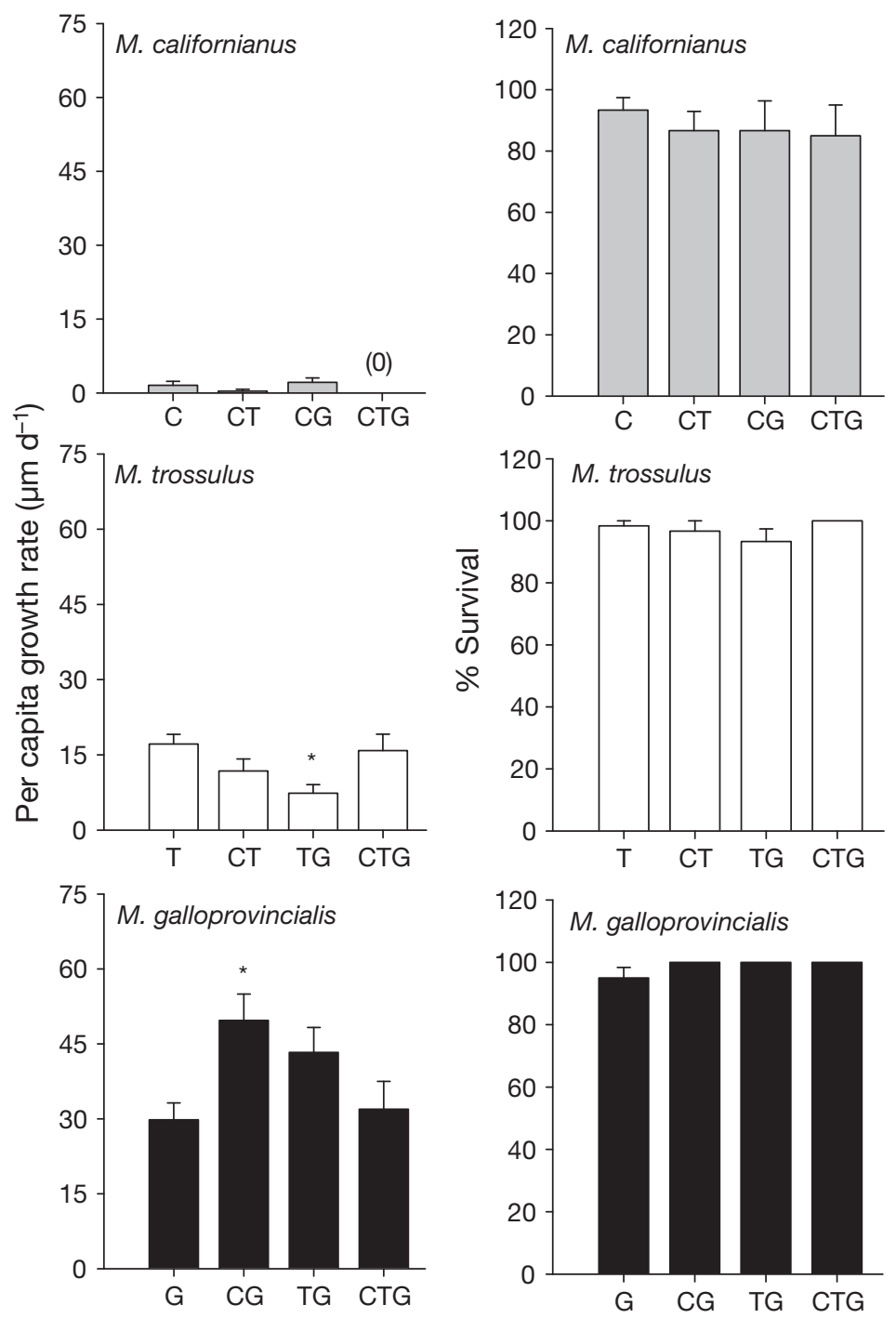

Fig. 2. Interference competition experiment. Mean per capita growth rates and percentage survival of 3 species of mussels within monocultures and polycultures. Bars indicate $+1 \mathrm{SE} .{ }^{*}$ Groups that differed significantly $(\mathrm{p}<0.05)$ from the monoculture controls based on Dunnett's post-hoc analyses of both the untransformed and rank-transformed data. See Fig. 1 for species abbreviations

galloprovincialis, was least proficient. Of the monocultures, only $M$. californianus and $M$. trossulus removed detectable amounts of chl a from the seston $\left(F_{3,20}=4.16\right.$, $\mathrm{p}=0.019$ ). Among polycultures, $M$. californianus combined with $M$. trossulus and the 3 -species polyculture removed the greatest $\mathrm{chl} a\left(F_{4,25}=22.9, \mathrm{p}<0.001\right)$. No filter feeding was evident in 2-species polycultures that included $M$. galloprovincialis. No differences in the percentage change of TPM among mussel cultures and the no-mussel control were detected $\left(F_{7,40}=1.96, \mathrm{p}=\right.$ 0.085 ; Fig. 5). However, monocultures of $M$. californianus and polycultures of $M$. californianus and $M$. trossulus removed the most POM from the seston $\left(F_{7,40}=4.25, \mathrm{p}=0.001\right)$. 

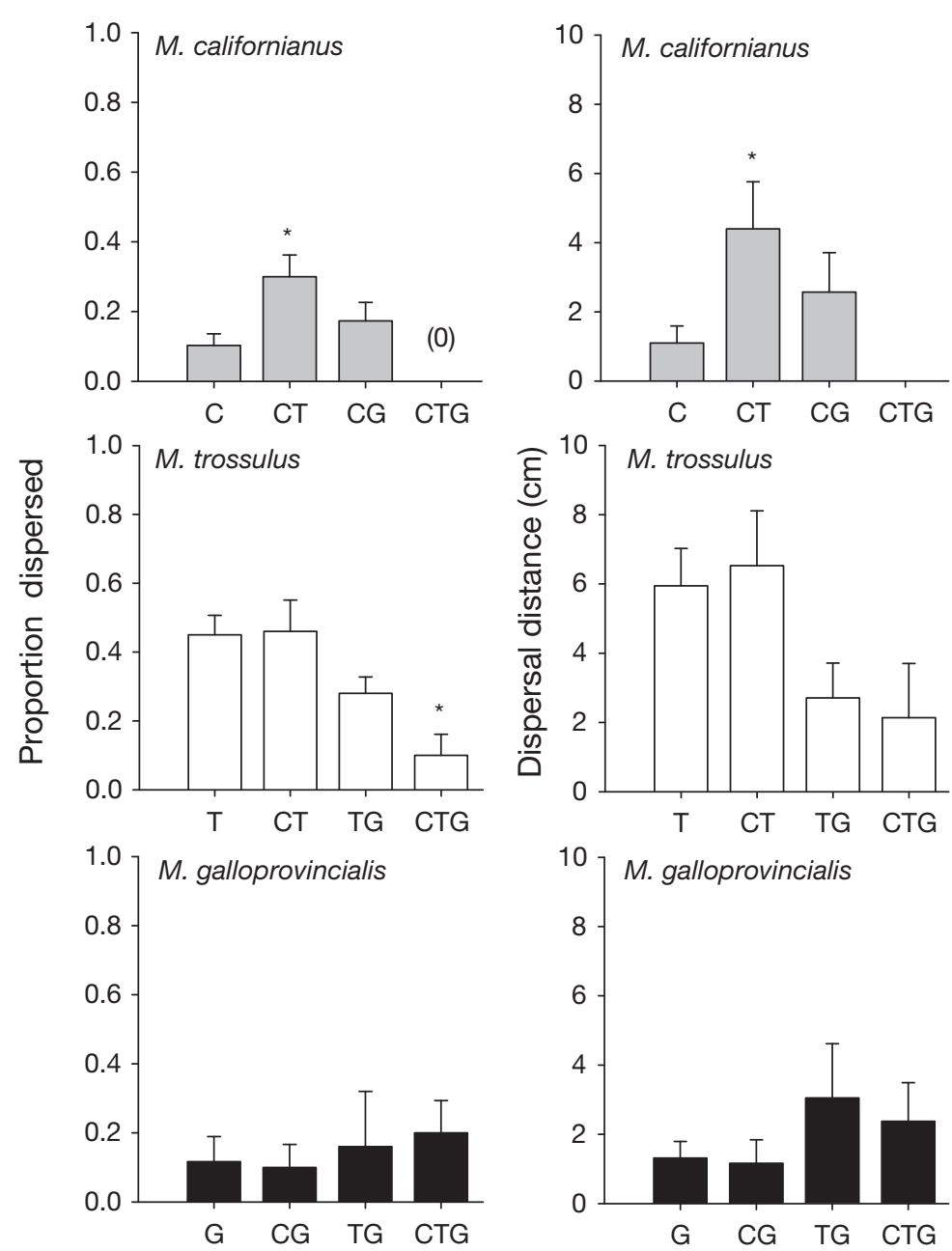

Fig. 3. Dispersal behaviors among native and invasive species of mussels showing the proportion of mussels found outside of mussel clumps and the mean distance traveled by mussels from clumps within monocultures and polycultures. Bars indicate $+1 \mathrm{SE}$. *Groups that differed significantly $(\mathrm{p}<$ 0.05) from the monoculture controls based on Dunnett's post-hoc analyses. See Fig. 1 for species abbreviations

\section{DISCUSSION}

\section{Competitive hierarchy among mussels}

Overall, we found compelling evidence that Mytilus galloprovincialis is competitively dominant over M. trossulus, where the invader consistently reduced the growth and survival of $M$. trossulus in both laboratory and field polycultures. Although the aim of this study was to identify specific mechanisms of interaction between mussels over relatively short time scales (4 to $8 \mathrm{wk}$ ), we were also able to detect populationlevel effects of competition with the invader as evidenced by the high mortality of $M$. trossulus. The duration of our experimental trials may have been too short to determine whether $M$. galloprovincialis is also competitively dominant over $M$. californianus. However, the rapid growth of the invader combined with increased recruitment of M. galloprovincialis might easily overwhelm $M$. californianus in rocky intertidal communities where the fastest-growing organisms often dominate the available substrate. Experimental mussel cultures in the laboratory and field differed in fluid dynamics, immersion time, and total mussel density, but despite differences in experimental conditions, M. galloprovincialis always outperformed its native congeners.

\section{Mechanisms of interspecific competition}

The invader interacted with native mussels primarily through interference competition. Mytilus galloprovincialis smothered heterospecific competitors, limited their mobility, and impeded filter feeding. Rather than density-mediated overgrowth of heterospecifics, the tendency to aggregate or disperse appeared to mediate competition between native and invasive mussels. Even without recruitment and growth of new individuals, mussels were able to smother one another by positioning themselves atop others. In the laboratory, mussels that did not disperse from the mussel clump incurred reduced growth rates or higher mortality when cultured with M. galloprovincialis. While M. galloprovincialis and $M$. californianus tended to be relatively non-mobile, $M$. trossulus dispersed from mussel clumps more frequently and at greater distances. Performance was consistently higher among $M$. trossulus that were found outside mussel clumps. However, M. trossulus dispersed less frequently in polyculture with M. galloprovincialis, a likely result of $M$. trossulus being prevented from dispersing by the byssal threads of M. galloprovincialis.

Similar patterns of clumping, smothering, and dispersal were observed in field monocultures and polycultures. Mytilus trossulus were loosely assembled with conspecifics and non-conspecifics, whereas M. californianus and M. galloprovincialis typically were tightly aggregated (Fig. 6). Harger (1968) hypothesized that highly mobile behavior among certain mussels may have had a definite benefit in calmer waters, where crawling above competitors or substrate may be necessary to prevent suffocation or 


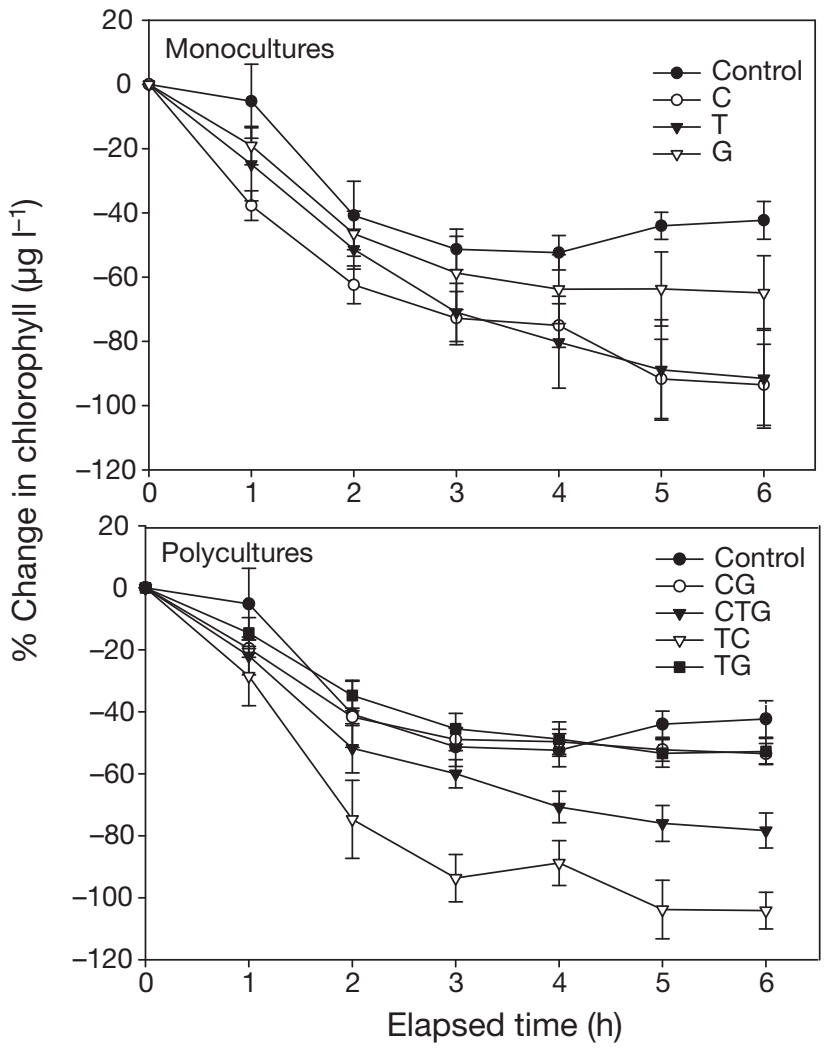

Fig. 4. Exploitation competition experiment. Chl a depletion by 3 species of mussels. Data with \pm SE bars are the average percentage change of in vivo chl a concentration standardized by total mussel dry mass. No mussels were present in control treatments. See Fig. 1 for species abbreviations

to find suitable areas for filter feeding. In contrast, dislodgement by wave force can be an important source of mortality in mussels, which is mediated by aggregation and increased attachment tenacity (Hunt \& Scheibling 2002). The tendency to aggregate in M. galloprovincialis could reflect weaker attachment ability or higher hydrodynamic loading of individuals (Rius \& McQuaid 2006). It may also explain the intraspecific density effects experienced by the invader in field cultures and the tendency of M. galloprovincialis to attach quickly to neighboring mussels (pers. obs.). Additional physical forces may mediate mussel movement and interference competition. In South Africa, competitive dynamics between the native Perna perna and invasive M. galloprovincialis vary in response to sand accumulation (Zardi et al. 2008), upwelling intensity (Xavier et al. 2007), and wave forces (Rius \& McQuaid 2006).

In addition to physical interference, we found that mussel behaviors were also involved in exploitation of shared food resources. Indeed, we found further evidence of interference competition among the 3 mussel species indicating that Mytilus galloprovincialis was

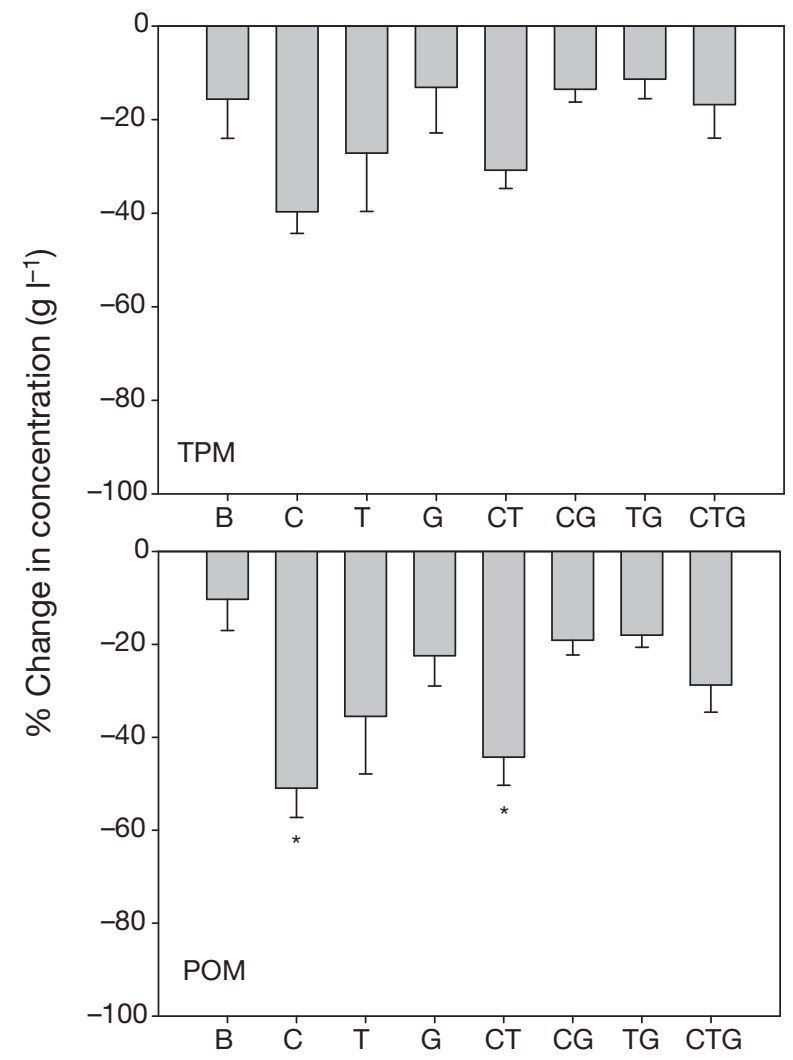

Fig. 5. Filter feeding on total particulate matter (TPM) and particulate organic matter (POM) by 3 species of mussels. Data are the average percentage change of concentrations standardized by total mussel dry mass. $\mathrm{B}=$ control. Error bars indicate +1 SE. *Groups that differed significantly $(p<0.05)$ from the no-mussel controls based on Dunnett's post-hoc analyses. See Fig. 1 for species abbreviations

behaviorally mediating chl a clearance rates in polycultures. The presence of $M$. galloprovincialis seemed to stop the consumption of chl a altogether rather than simply reducing the clearance rate relative to its density in polyculture. Although the scope of the present study was limited to revealing interference effects of M. galloprovincialis on native competitors, the seston clearance trials demonstrated different feeding rates among the 3 species, suggesting that exploitation might be an important mechanism of competition. However, the mussel with the fastest growth rate, M. galloprovincialis, exhibited the slowest feeding rate. These results were surprising and contradict other studies that have demonstrated a strong exploitative advantage of $M$. galloprovincialis over other mussel competitors (Griffiths et al. 1992, Hilbish et al. 1994). M. galloprovincialis in the experiments presented here may have been more occupied with byssal attachment than feeding, and clearance rates may increase with longer experimental duration (Byrnes 2008). 
Field

a

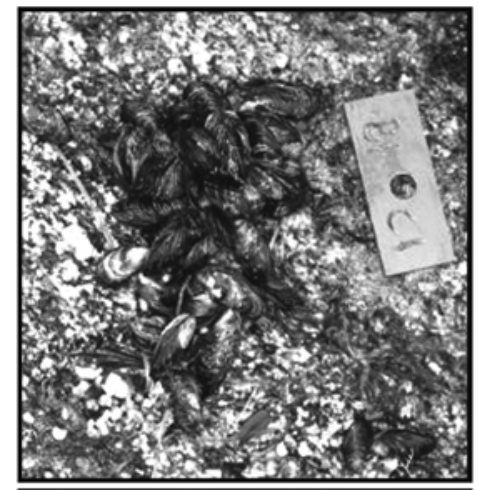

$\mathrm{b}$

C

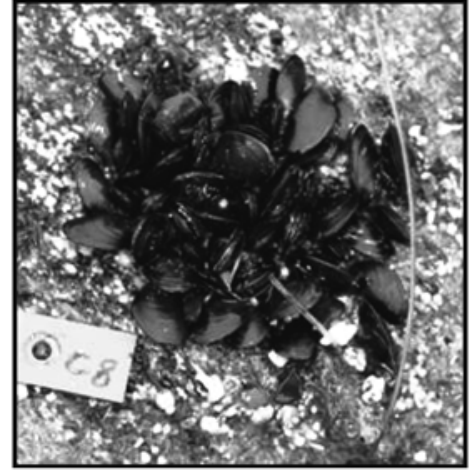

Fig. 6. Photographs of representative mussel clumping behavior in field and laboratory monocultures of (a) Mytilus californianus, (b) M. trossulus, and (c) M. galloprovincialis

\section{Consequences of interspecific competition}

Interspecific competition has long been recognized as an important force regulating rocky intertidal community structure (Connell 1961), but it does not appear to be limiting the spread of Mytilus galloprovincialis. The rapid growth rate, mechanical interference, and behavioral dominance of $M$. galloprovincialis will likely enable further invasion in the Pacific Northwest. M. galloprovincialis appears to be contributing to the displacement of the native M. trossulus (Geller 1999). Regional extinctions caused by competition between native and invasive species are rare (Davis 2003), but increasing populations of $M$. galloprovincialis may have dramatic community-level consequences for rocky intertidal communities. In particular, an extensive invasion of M. galloprovincialis may reduce the diversity and richness of epiphytic algae and sessile invertebrates associated with the shells of mussels (Shinen \& Morgan unpubl.). Furthermore, the differences in filter-feeding rate between native and invasive mussels suggest that displacement of $M$. trossulus by $M$. galloprovincialis may decrease or disrupt community biofiltration rates, which may affect a variety of other native intertidal species. Invasive bivalves that alter phytoplankton distribution and abundance can have dramatic and unpredictable effects on multiple trophic levels and ecosystem scales (Noonburg et al. 2003, Kimmerer 2006). These results illustrate the importance of elucidating interaction mechanisms to understand invasion resistance and anticipate the potential impacts of invasive species.

Despite our evidence that Mytilus galloprovincialis is a strong competitor among native mussels, the invader is still only weakly established in central and northern California. The current extent of the invasion likely reflects a balance between predation and recruitment rates. Persistent oceanic upwelling and offshore larval transport in the zone of mussel sympatry limits recruitment (Connolly et al. 2001) and may be limiting the establishment of $M$. galloprovincialis. On the west coast of South Africa, where M. galloprovincialis has been so profoundly successful, the high reproductive output of M. galloprovincialis, coupled with larval retention, translates directly into dramatically high rates of recruitment to the shore (Harris et al. 1998). Additionally, predation is strong force limiting the invasion of $M$. galloprovincialis. The dogwhelk Nucella ostrina selectively eats M. galloprovincialis, irrespective of the density of the invader relative to native mussels (Shinen et al. 2009). However, aquaculture of $M$. galloprovincialis has increased exponentially since the 1950s (Food and Agriculture Organization of the United Nations 2007), increasing larval supply and recruitment potential far north of the current invasion front. Increases in the populations $M$. galloprovincialis will likely coincide with increases in the importance of interspecific competition in resident rocky intertidal communities.

Our findings reinforce an emerging consensus among ecologists that invasion resistance cannot be predicted from simple rules and is instead a function of 
numerous interacting mechanisms (D'Antonio 1993, Thebaud et al. 1996). In the present study, closely related congeners all exhibited varying responses to inter- and intraspecific density effects that would not likely have been predicted without manipulative experiments that helped to identify the mechanisms of competition. These results may provide a cautionary tale for other invasion studies involving closely related natives and invaders, since relatedness is not always an accurate predictor of competitive ability and invasiveness (Lambrinos 2002). Moreover, studies that use a comparative approach between closely related native and invasive species can provide valuable insights linking coexistence mechanisms and invasion success. For instance, understanding the mechanisms of interspecific interactions between native and invasive species may help to predict the likely impact of an invasion in a native community. Finally, discerning the mechanisms of competition between native and invasive species may also help direct management efforts to limit the spread or reduce the impacts of exotic invaders.

Acknowledgements. We thank M. A. Holyoak and J. J. Stachowicz for commenting on the experimental design and an earlier draft of the manuscript. Special thanks to M. C. Vasquez, B. G. Miner, J. L. Fisher, A. J. Mace, E. A. Fairbairn, Y. Henneberry, J. E. Byrnes, and M. E. Bracken for their invaluable advice and assistance in the laboratory and the field. Thanks also to E. Sanford, J. Sones, and S. A. Thompson for mussel collections.

\section{LITERATURE CITED}

Abramoff MD, Magelhaes PJ, Ram SJ (2004) Image processing with ImageJ. Biophotonics Int 11:36-42

Bownes SJ, McQuaid CD (2006) Will the invasive mussel Mytilus galloprovincialis Lamarck replace the indigenous Perna perna L. on the south coast of South Africa? J Exp Mar Biol Ecol 338:140-151

Braby CE, Somero GN (2006) Ecological gradients and relative abundance of native (Mytilus trossulus) and invasive (Mytilus galloprovincialis) blue mussels in the California hybrid zone. Mar Biol 148:1249-1262

Branch GM, Steffani CN (2004) Can we predict the effects of alien species? A case-history of the invasion of South Africa by Mytilus galloprovincialis (Lamarck). J Exp Mar Biol Ecol 300:189-215

Brown BJ, Mitchell RJ, Graham SA (2002) Competition for pollination between an invasive species (purple loosestrife) and a native congener. Ecology 83:2328-2336

Byrnes JE (2008) Patterns and consequences of changing biodiversity in coastal marine food webs. PhD thesis, University of California Davis

> Callaway RM, Aschehoug ET (2000) Invasive plants versus their new and old neighbors: a mechanism for exotic invasion. Science 290:521-523

> Carlton JT (1996) Pattern, process, and prediction in marine invasion ecology. Biol Conserv 78:97-106

> Castilla JC, Guiñez R, Caro AU, Ortiz V (2004) Invasion of a rocky intertidal shore by the tunicate Pyura praeputialis in the Bay of Antofagasta, Chile. Proc Natl Acad Sci USA 101:8517-8524

Coe WR, Fox DL (1942) Biology of the California sea mussel (Mytilus californianus). I. Influence of temperature, food supply, sex, and age on the rate of growth. J Exp Zool 90:1-30

Connell JH (1961) Effects of competition and predation by Thais lapillus, and other factors on natural populations of the barnacle Balanus balanoides. Ecol Monogr 31:61-104

Connell JH (1983) On the prevalence and relative importance of interspecific competition: evidence from field experiments. Am Nat 122:661-696

Connolly SR, Menge BA, Roughgarden J (2001) A latitudinal gradient in recruitment of intertidal invertebrates in the northeast Pacific Ocean. Ecology 82:1799-1813

Cousens R, O'Neill M (1993) Density dependence of replacement series experiments. Oikos 66:347-352

> D'Antonio CM (1993) Mechanisms controlling invasion of coastal plant communities by the alien succulent Carpobrotus edulis. Ecology 74:83-95

> Davis MA (2003) Biotic globalization: does competition from introduced species threaten biodiversity? Bioscience 53: 481-489

Duyck PF, David P, Junod G, Brunel C, Dupont R, Quilici S (2006) Importance of competition mechanisms in successive invasions by polyphagous tephritids in La Reunion. Ecology 87:1770-1780

Elton CS (1958) The ecology of invasions by animals and plants. Methuen, London

Food and Agriculture Organization of the United Nations (2007) Cultured Aquatic Species Information Programme: Mytilus galloprovincialis (Lamark, 1819). www.fao.org/ fishery/culturedspecies/Mytilus_galloprovincialis/en

Frechette M, Despland E (1999) Impaired shell gaping and food depletion as mechanisms of asymmetric competition in mussels. Ecoscience 6:1-11

Fridley JD, Stachowicz JJ, Naeem S, Sax DF and others (2007) The invasion paradox: reconciling pattern and process in species invasions. Ecology 88:3-17

Geller JB (1999) Decline of a native mussel masked by sibling species invasion. Conserv Biol 13:661-664

Griffiths CL, Hockey PAR, Van Erkom Schurink C, Roux PJL (1992) Marine invasive aliens on South African shores: implications for community structure and trophic functioning. S Afr J Mar Sci 12:713-722

> Grosholz E (2002) Ecological and evolutionary consequences of coastal invasions. Trends Ecol Evol 17:22-27

> Hanekom N (2008) Invasion of an indigenous Perna perna mussel bed on the south coast of South Africa by an alien mussel Mytilus galloprovincialis and its effect on the associated fauna. Biol Invasions 10:233-244

Harger JRE (1968) The role of behavioral traits in influencing the distribution of two species of sea mussel, Mytilus edulis and Mytilus californianus. Veliger 11:45-49

Harris JM, Branch GM, Elliott BL, Currie B and others (1998) Spatial and temporal variability in recruitment of intertidal mussels around the coast of southern Africa. S Afr J Zool 33:1-11

Hilbish TJ, Bayne BL, Day A (1994) Genetics of physiological differentiation within the marine mussel genus Mytilus. Evolution 48:267-286

> Hollebone AL, Hay ME (2007) Propagule pressure of an invasive crab overwhelms native biotic resistance. Mar Ecol Prog Ser 342:191-196

Hunt HL, Scheibling RE (2002) Movement and wave dislodgement of mussels on a wave-exposed rocky shore. Veliger 45:273-277 
Johnson SB, Geller JB (2006) Larval settlement can explain the adult distribution of Mytilus californianus Conrad but not of $M$. galloprovincialis Lamarck or M. trossulus Gould in Moss Landing, central California: evidence from genetic identification of spat. J Exp Mar Biol Ecol 328: 136-145

Jolliffe PA (2000) The replacement series. J Ecol 88:371-385

Kimmerer WJ (2006) Response of anchovies dampens effects of the invasive bivalve Corbula amurensis on the San Francisco Estuary foodweb. Mar Ecol Prog Ser 324: 207-218

Lambrinos JG (2002) The variable invasive success of Cortaderia species in a complex landscape. Ecology 83: $518-529$

Levine JM (2000) Species diversity and biological invasions: relating local process to community pattern. Science 288: 852-854

Levine JM, D'Antonio CM (1999) Elton revisited: a review of evidence linking diversity and invasibility. Oikos 87:15-26

Martel AL, Auffrey LM, Robles CD, Honda BM (2000) Identification of settling and early postlarval stages of mussels (Mytilus spp.) from the Pacific coast of North America, using prodissoconch morphology and genomic DNA. Mar Biol 137:811-818

McDonald JH, Seed R, Koehn RK (1991) Allozymes and morphometric characters of three species of Mytilus in the northern and southern hemispheres. Mar Biol 111: 323-333

Moore JL, Mouquet N, Lawton JH, Loreau M (2001) Coexistence, saturation and invasion resistance in simulated plant assemblages. Oikos 94:303-314

Morrison LW (2000) Mechanisms of interspecific competition among invasive and two native fire ants. Oikos 90:238-252

Naeem S, Knops JMH, Tilman D, Howe KM, Kennedy T, Gale S (2000) Plant diversity increases resistance to invasion in the absence of covarying extrinsic factors. Oikos 91: $97-108$

Noonburg EG, Shuter BJ, Abrams PA (2003) Indirect effects of zebra mussels (Dreissena polymorpha) on the planktonic food web. Can J Fish Aquat Sci 60:1353-1368

Rawson PD, Agrawal V, Hilbish TJ (1999) Hybridization between the blue mussels Mytilus galloprovincialis and $M$. trossulus along the Pacific coast of North America: evidence for limited introgression. Mar Biol 134:201-211

Rius M, McQuaid CD (2006) Wave action and competitive interaction between the invasive mussel Mytilus galloprovincialis and the indigenous Perna perna in South Africa. Mar Biol 150:69-78

Sanjuan A, Zapata C, Alvarez G (1997) Genetic differentiation in Mytilus galloprovincialis Lmk. throughout the world. Ophelia 47:13-31

Editorial responsibility: Richard Osman,

Edgewater, Maryland, USA
Sarver SK, Foltz DW (1993) Genetic population structure of a species' complex of blue mussels (Mytilus spp.). Mar Biol 117:105-112

Shinen JL, Morgan SG, Chan AL (2009) Invasion resistance on rocky shores: direct and indirect effects of three native predators on an exotic and a native prey species. Mar Ecol Prog Ser 378:47-54

Stachowicz JJ, Fried H, Osman RW, Whitlatch RB (2002) Biodiversity, invasion resistance, and marine ecosystem function: reconciling pattern and process. Ecology 83: $2575-2590$

Steffani CN, Branch GM (2005) Mechanisms and consequences of competition between an alien mussel, Mytilus galloprovincialis, and an indigenous limpet, Scutellastra argenvillei. J Exp Mar Biol Ecol 317:127-142

Stohlgren TJ, Binkley D, Chong GW, Kalkhan MA and others (1999) Exotic plant species invade hot spots of native plant diversity. Ecol Monogr 69:25-46

Suchanek TH, Geller JB, Kreiser BR, Mitton JB (1997) Zoogeographic distributions of the sibling species Mytilus galloprovincialis and $M$. trossulus (Bivalvia: Mytilidae) and their hybrids in the North Pacific. Biol Bull 193:187-194

> Thebaud C, Finzi AC, Affre L, Debussche M, Escarre J (1996) Assessing why two introduced Conyza differ in their ability to invade Mediterranean old fields. Ecology 77: 791-804

Underwood AJ (1986) The analysis of competition by field experiments. In; Kikkawa J, Anderson DJ (eds) Community ecology: pattern and process. Blackwell, Melbourne, p 240-268

Van Erkom Schurink C, Griffiths CL (1990) Marine mussels of southern Africa: their distribution patterns, standing stocks, exploitation and culture. J Shellfish Res 9:75-85

> Velasco LA, Navarro JM (2005) Feeding physiology of two bivalves under laboratory and field conditions in response to variable food concentrations. Mar Ecol Prog Ser 291: 115-124

Wonham MJ (2004) Mini-review: distribution of the Mediterranean mussel Mytilus galloprovincialis (Bivalvia: Mytilidae) and hybrids in the northeast Pacific. J Shellfish Res 23:535-543

Xavier BM, Branch GM, Wieters E (2007) Abundance, growth and recruitment of Mytilus galloprovincialis on the west coast of South Africa in relation to upwelling. Mar Ecol Prog Ser 346:189-201

Zar JH (1974) Biostatistical analysis. Prentice Hall, Englewood Cliffs

Zardi GI, Nicastro KR, McQuaid CD, Erlandsson J (2008) Sand and wave induced mortality in invasive (Mytilus galloprovincialis) and indigenous (Perna perna) mussels. Mar Biol 153:853-858

Submitted: June 25, 2008; Accepted: February 17, 2009

Proofs received from author(s): May 8, 2009 